\title{
(t)
}

\section{CONCEPÇÃO DE CIDADE NA OBRA DE CLÁSSICOS DA TEORIA SOCIAL}

Design of the city on classical social theory

\author{
Gabriela Lema Icasuriaga' \\ Maria Helena Rauta Ramos ${ }^{2}$
}

\section{RESUMO}

Buscamos, na Teoria Social Clássica, traços da gênese e desenvolvimento da cidade sob o modo de produção capitalista. Indicamos elementos, examinando diferentes perspectivas teóricas (Marx, Engels, Durkheim e Weber), que contribuem para a explicação e análise dos processos urbanos contemporâneos.

\section{PALAVRAS-CHAVE}

Cidade. Teoria Social. Urbanização capitalista.

\section{ABSTRACT}

In classical social theory we look forward genesis's traces of the city under the capitalist mode of production, while indicative elements for the understanding from different theoretical perspectives that contribute to the analysis of contemporary urban processes.

\section{KEYWORDS}

City. SocialTheory. Capitalist urbanization.

Submetido: 15/6/2012

Aceito: $20 / 8 / 2012$

\footnotetext{
${ }^{1}$ Doutora em Serviço Social (UFRJ), Professora da Universidade Federal do Rio de Janeiro. E-mail: <gabrielalemai@gmail.com>.

2 Doutora em Serviço Social (PUC/SP), Pesquisadora e Professora aposentada da Escola de Serviço Social da UFRJ. E-mail: <rauta.ramos@gmail.com>.
} 


\section{INTRODUÇÃO}

Embora os estudos sobre a cidade tenham ocupado um espaço periférico na formação acadêmica e interventiva do Serviço So$\mathrm{cial}^{3}$, a temática vem adquirindo lugar de destaque a partir dos processos de reestruturação produtiva em nível mundial que colocam as cidades dentro da lógica territorial do atual estágio do desenvolvimento capitalista (ICASURIAGA, 1997). São privilegiadas, nesse processo, as cidades que oferecem infraestruturas, equipamentos e serviços avançados para facilitar a locação de operações econômicas transnacionais, exigindo, como precondição, garantia de segurança física, material e financeira. Como o processo histórico de construção da Cidade Moderna inicia-se com a emergência do Capitalismo, julgamos fundamental delinear os traços de sua gênese e desenvolvimento no pensamento dos principais expoentes da Teoria Social clássica, com o propósito de oferecer subsídios para leituras mais consistentes sobre a temática em tela.

A partir do quadro da Revolução Industrial, existem diferentes explicações sobre o fenômeno urbano, segundo a perspectiva teórica de orientação. Desse modo, fizemos um esforço para extrair, da obra dos clássicos da Teoria Social (Marx, Engels, Durkheim e Weber) ${ }^{4}$, elementos indicativos para explicação da cidade, na medida em que suas concepções fundamentam as diferentes perspectivas teóricas contemporâneas e, ao mesmo tempo, oferecem possibilidades distintas para a análise da cidade capitalista.

Concernentes ao horizonte histórico do momento do desenvolvimento do Capitalismo, em que se situa a obra desses autores, pode haver limites no conteúdo abordado, mas não na potencialidade explicativa dos conceitos e categorias utilizados. Embora sejam análises críticas do capitalismo, está subjacente às concepções desses diferentes autores, sua orientação política,

\footnotetext{
${ }^{3} \mathrm{O}$ texto que apresentamos, de caráter teórico conceitual, fornece alguns subsídios para aqueles que estão iniciando seus estudos e práticas na temática urbana. Tem, portanto, finalidade propedêutica, e decorre de estudos sistemáticos no âmbito de núcleo de pesquisa e extensão universitária.

${ }^{4}$ Souza (2000, p. 11) observa que Max Weber e Karl Marx são os autores mais citados nas teses de pós-graduação na área de ciências humanas.
} 
seja vinculado aos interesses do proletariado e à emancipação social (Marx e Engels), seja vinculado à preservação dos interesses da burguesia (Durkheim e Weber). É imprescindível para a análise da sociedade contemporânea a busca dessas chaves explicativas, na medida em que transcendem a complexidade social de seu tempo, e é um contraponto à fragmentação teórica e ao reducionismo empirista que se veem presentes no pensamento pós-moderno.

\section{CONCEPÇÃO DE CIDADE EM DURKHEIM}

A influência de Durkheim é expressiva nos estudos urbanos contemporâneos 5 , a referência à cidade permeia a sua obra, especialmente naquela intitulada $\mathrm{Da}$ divisão do trabalho social, publicada, originalmente, em 1893. Esse fundador da sociologia francesa tinha como objeto de investigação a sociedade burguesa, produto da revolução industrial.

Desde o final da segunda metade do século XIX (a partir de 1848), as lutas de classes manifestavam-se não mais, fundamentalmente, entre aristocracia feudal e burguesia em ascensão, mas declaradamente entre burguesia (já constituída em classe dominante) e o nascente movimento operário. Desse modo, Durkheim viu surgir "[...] o que se denominava questão social, ou seja, as disputas e conflitos decorrentes da oposição entre o capital e o trabalho, vale dizer, entre patrão e empregado, entre burguesia e proletariado" (RODRIGUES, 1998, p. 9).

Sua principal tese encontra-se em Da divisão do trabalho social (DURKHEIM, 1999), quando assimila a gênese e desenvolvimento da sociedade burguesa à solidariedade orgânica, produzida pela divisão do trabalho, distinguindo-a das sociedades tradicionais regidas pela solidariedade mecânica (sociedades em que a divisão do trabalho é praticamente inexistente).

Com base na evolução dos organismos animais, Durkheim (1999) reputa que, na sociedade em que a divisão do trabalho social é bastante desenvolvida, a solidariedade orgânica é análoga àquela observada nos organismos dos animais superiores, apresentando

${ }^{5}$ Nesse sentido, ver, entre outros, Giddens (1997), principalmente os capítulos 3:
A Sociologia Política de Durkheim e 4: Durkheim e a questão do individualismo. 
cada órgão uma fisionomia particular, uma autonomia. Ou seja, quanto mais desenvolvida for a individualidade das partes, maior se apresenta a unidade do organismo ${ }^{6}$. E, pensando nessas inúmeras relações, o autor propõe que o Estado disponha de uma regulamentação jurídica, medida necessária para suprimir os conflitos sociais, provocados pela divisão social do trabalho7:

Quanto mais os membros de uma sociedade são solidários, mas mantém relações diversas seja uns com os outros, seja com o grupo tomado coletivamente, pois, se seus encontros fossem raros, só dependeriam uns dos outros de maneira intermitente e fraca. Por outro lado, o número dessas relações é necessariamente proporcional ao das regras jurídicas que as determinam. De fato, a vida social, onde quer que exista de maneira duradoura, tende inevitavelmente a tomar uma forma definida e a se organizar e o direito nada mais é que essa mesma organização no que ela tem de mais estável e de mais preciso (DURKHEIM, 1999, p. 31).

A partir do quadro de desenvolvimento da divisão do trabalho social, constituído sob a Revolução Industrial, a cidade é descrita, por Durkheim (1999), na sua particularidade sobre o território. Ele dá ênfase à aglomeração de pessoas, de meios de produ-

\footnotetext{
${ }^{6} \mathrm{Na}$ sociedade em que não existe um grau elevado de desenvolvimento da divisão de trabalho, o indivíduo encontra-se vinculado diretamente à sociedade, sem quaisquer mediações. A sociedade se apresenta como um conjunto de crenças e sentimentos comuns, em grau diferenciado de organização. Quando as ideias e as tendências, pertencentes a toda a sociedade, são em maior número e mais intensas que as possuídas individualmente por seus membros, prevalece a solidariedade mecânica, porque, para o autor, são integralmente análogos os laços que unem o indivíduo à sociedade e aqueles que ligam a coisa à pessoa. Na verdade, os indivíduos são mais objetos da personalidade coletiva do que sujeitos com autonomia.

7 Por conseguinte, em Da divisão do trabalho social, Durkheim (1999) elabora uma classificação das regras jurídicas, tratadas como fato social, na medida em que o direito reproduziria as principais formas de solidariedade social, desvendando as suas correspondentes modalidades: direito repressivo (o direito penal) e direito restitutivo (as demais modalidades de direito). Ele trata a propriedade privada dentro das relações regulamentadas pelo direito restitutivo, que ele denomina de negativas. Ou seja, as relações restitutivas assumiriam "[...] duas formas muito diferentes: ora são negativas e se reduzem a uma pura abstenção, ora são positivas ou de cooperação, caracterizando duas espécies de solidariedade social" (DURKHEIM, 1999, p. 90).
} 
ção, como também valoriza o papel dos meios de comunicação e transporte ${ }^{8}$. Durkheim (1999) parece enunciar que a divisão do trabalho não ocorre somente no processo de produção, "[...] mundo econômico [...]", mas se generaliza, expandindo-se na sociedade, "[...] as funções políticas, administrativas e jurídicas [...]", alcançando os seus demais ciclos da produção (processo ampliado de produção), ao afirmar que "[...] a divisão do trabaIho não é específica do mundo econômico: podemos observar sua influência crescente nas regiões mais diferentes da sociedade. As funções políticas, administrativas, jurídicas especializam-se cada vez mais" (DURKHEIM, 1999, p. 2). Para ele, a divisão do trabalho tem como função fazer crescer, simultaneamente, "[...] a força produtiva e a habilidade do trabalhador, ela é condição necessária do desenvolvimento intelectual e material das sociedades; é a fonte da civilização" (DURKHEIM, 1999, p. 14).

Observamos que faz uma referência, no seu prefácio à segunda edição da obra Da divisão do trabalho social, referindo-se às sociedades da Idade Média, e o papel da indústria e do comércio na conquista das cidades livres:

A burguesia no século XIII, explica Levasseur, 'era composta exclusivamente de gente de ofício. A classe dos magistrados e dos juristas apenas começava a se formar; os homens de estudo ainda pertenciam ao clero; a quantidade dos que viviam de rendas era muito pequena, porque a propriedade territorial ainda estava quase toda em mãos dos nobres; aos plebeus restava apenas o trabalho do ateliê e do balcão, e foi pela indústria e pelo comércio que eles conquistaram uma posição no reino' (DURKHEIM, 1999, p. 28).

Numa alusão explícita à cidade, Durkheim acrescenta:

O mesmo aconteceu na Alemanha. Burguês e citadino eram sinônimos e, de outro lado, sabemos que as cidades alemãs formaram-se em torno de mercados permanentes, abertos por um senhor num ponto de seu domínio. A população que vinha se agrupar em torno desses mercados e que se tornou a população

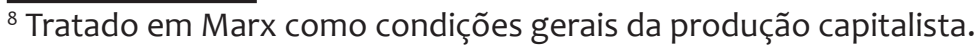


urbana era, pois, quase exclusivamente composta de artesãos e mercadores. Por isso as palavras forenses ou mercatores serviam para designar indiferentemente os habitantes das cidades, e o jus civile ou direito urbano é frequentemente chamado de jus fori ou direito do mercado. A organização dos ofícios e do comércio parece, pois, ter sido a organização primitiva da burguesia europeia (DURKHEIM, 1999, p. 28).

Mas, ele vai se referir especificamente ao urbano, no capítulo 6 (Livro I), sob o título Preponderância progressiva da solidariedade orgânica e suas consequências (DURKHEIM, 1999, p. 157-184). Diferenciando do terreno propício no qual ocorre a solidariedade mecânica - clãs, tribos e aldeias -, porque, na sociedade regida pela solidariedade orgânica, "[...] os indivíduos não são mais agrupados segundo suas relações de descendência, mas segundo a natureza particular da atividade social a que se consagram. Seu meio natural e necessário não é mais o meio natal, mas o meio profissional" (DURKHEIM, 1999, p. 166).

Os habitantes, num determinado território, desenvolvem vínculos intensificados com o aumento da divisão do trabalho, não são mais os laços de consanguinidade; está nascendo o citadino:

[...] cada divisão territorial tem usos e costumes especiais, uma vida que lhe é própria. Ela exerce, assim, sobre os indivíduos que são imbuídos de seu espírito, uma atração que tende a mantê-los no lugar e, ao contrário, a repelir os outros. Mas, dentro de um mesmo país, essas diferenças não poderiam ser nem muito numerosas, nem muito nítidas. Os segmentos são, portanto, mais abertos uns aos outros (DURKHEIM, 1999, p. 170-171).

A partir da Idade Média, com a formação das cidades, Durkheim (1999, p. 171) registra que "[...] os artesãos estrangeiros circulam tão facilmente e tão longe quanto as mercadorias". E surgem agregados parciais, integrados a agregados mais amplos, particularizando-os, mesmo que dentro de uma unidade. As organizações familiares desaparecem, fazendo-se acompanhar das religiões locais.

Cada cidade, com seus arredores imediatos, forma um grupo no interior do qual o trabalho é dividido, mas que se esforça por ser auto-suficien- 
te. 'A cidade torna-se, na medida do possível, o centro eclesiástico, político e militar das aldeias vizinhas', diz Schmoller. Ela aspira a desenvolver todas as indústrias para abastecer o campo, do mesmo modo que concentrar em seu território o comércio e os transportes. Ao mesmo tempo, no interior da cidade, os habitantes são agrupados de acordo com sua profissão; cada corporação de ofício é como uma cidade que tem sua vida própria (DURKHEIM, 1999, p. 172).

Durkheim (1999, p. 172) descreve, a partir de sua observação empírica, como o movimento urbano se alastra, produzindo:

a) Cidades capitais: "[...] na capital, concentram-se, hoje mais que outrora, as forças ativas do governo central, as artes, a literatura, as grandes operações de crédito"; e igualmente à capital, as demais capitais das provinciais se adensam em função da concentração da administração provincial, as coletorias e as escolas;

b) Cidades portos: "[...] nos grandes portos concentram-se mais que antes todas as exportações e importações";

c) Cidades comerciais: "Centenas de pequenas praças de comércio, traficando grãos e gado, prosperam e crescem”;

d) Cidades políticas: "Ao passo que, outrora, cada cidade tinha muralhas e fossos, agora algumas grandes fortalezas se encarregam de proteger todo o país";

e) Outras tantas particularidades de cidades: "As diferentes cidades tendem cada vez mais a certas especialidades, de tal modo que hoje as distinguimos em cidades universitárias, de funcionários, de fábricas, de comércio, de águas, de gente que vive de rendas".

Esse clássico da Sociologia dá um destaque para os grandes centros industriais:

Em certos pontos ou em certas regiões concentram-se as grandes indústrias: construção de máquinas, fiações, manufaturas de tecidos, curtumes, alto-fornos, indústria açucareira, que trabalham para todo o país. Aí se estabeleceram escolas especiais, aí a população operária se instala, aí a construção das máquinas se concentra, enquanto as comunicações 
e a organização do crédito se acomodam às circunstâncias particulares (DURKHEIM, 1999, p. 173).

No capítulo 2, As causas, do Livro II, intitulado As causas e as condições (DURKHEIM, 1999, p. 223-280), sob o título As causas, ele vai relacionar divisão do trabalho à densidade das relações sociais, denominando de densidade moral ou dinâmica da sociedade esse último processo social:

Mas essa aproximação moral só pode produzir seu efeito se a própria distância entre os indivíduos tiver diminuído, como quer que seja. Portanto, a densidade moral não pode aumentar sem que a densidade material aumente ao mesmo tempo, e esta pode servir para medir aquela (DURKHEIM, 1999, p. 253).

Durkheim (1999, p. 254) afirma que no desenvolvimento do processo histórico, foi sendo produzida uma "[...] condensação progressiva [...]", mediante:

1) O fenômeno da concentração populacional em um determinado território: "[...] entre os povos mais avançados a população vai se concentrando cada vez mais";

2) A formação da cidade e pelo seu desenvolvimento: "[...] as cidades sempre resultam da necessidade que impele os indivíduos a manterem constantemente o contato mais íntimo uns com os outros";

3) A quantidade e rapidez das vias de comunicação: "Suprimindo ou diminuindo os vazios que separam os segmentos sociais, elas aumentam a densidade das sociedades".

Também faz alusão ao papel das diferentes vias de comunicação (inclusive marítimas e fluviais), suporte das relações entre seus habitantes (além de dar destaque aos recursos naturais - oceanos, cursos de água, de que o solo é portador - e aos povos vizinhos).

Durkheim (1999) pensa o futuro da organização social baseada, cada vez mais, na organização profissional, sendo a solidariedade mecânica regredida na medida em que avança a solidariedade orgânica. Aponta que a divisão do trabalho social vai tornar coerentes as sociedades em que vivemos, determinando as características constitutivas de sua estrutura. E na medida em que o Estado, por meio do di- 
reito, regulamente os conflitos sociais, advindos com novas divisões do trabalho, alcança-se um equilíbrio nas relações sociais.

No pensamento desse clássico, encontramos uma preocupação com as determinações objetivas e subjetivas sob as quais as relações sociais se modificam, produzindo, segundo ele, relações regidas pela solidariedade orgânica, produto da divisão do trabalho. Para ele, os indivíduos se diferenciam em razão das condições externas às quais se encontram submetidos. "Trata-se, porém, de saber se esta diversidade, que, sem dúvida, tem suas relações com a divisão do trabalho, basta para constituí-la" (DURKHEIM, 1999, p. 260). Daí ele faz uma passagem para a tese do evolucionismo: a luta das espécies movida pela sobrevivência. "Se o trabalho se divide mais à medida que as sociedades se tornam mais volumosas e mais densas, não é porque, nelas, as circunstâncias externas sejam mais variadas, mas porque a luta pela vida é mais ardente" (DURKHEIM, 1999, p. 263).

Nesse ponto de sua obra, Durkheim (1999) aborda questões relativas às tensões, às divergências e aos conflitos. Porém sua perspectiva nessa análise é individual e referida, na sociedade, à concorrência entre funções. Diz ele:

No entanto, quanto mais as funções se aproximam, mais há entre elas pontos de contato, mais, por conseguinte, elas são expostas a se combaterem [...]. Nunca o magistrado concorrerá com o industrial; mas o cervejeiro e o vinhateiro, o fabricante de tecidos e o fabricante de sedas, o poeta e o músico muitas vezes se esforçam por se suplantar um ao outro. Quanto aos que desempenham exatamente a mesma função, só podem prosperar em detrimento uns dos outros (DURKHEIM, 1999, p. 264-265).

E o espaço privilegiado desta luta entre indivíduos é a cidade, como também se espraia por todo o conjunto da sociedade: “Assim acontece não só no interior de cada cidade, mas em toda a extensão da sociedade" (DURKHEIM, 1999, p. 265). Defende que há relação entre o acirramento das lutas e conflitos, e o aumento da divisão do trabalho. Surgidos, nesse contexto, para seu controle, é necessário o Estado legislar, normatizando os problemas advindos das novas divisões do trabalho. 
Partindo da circulação, entende que o desenvolvimento do centro industrial está relacionado à extensão do mercado, determinado "[...] pela extensão das necessidades que se trata de satisfazer" (DURKHEIM, 1999, p. 265); pelo grau de desenvolvimento dos meios de produção, decorrente da sua potência; e pelo grau de desenvolvimento das vias de comunicação.

O que chama nossa atenção neste autor é a sua concepção de propriedade privada, cuja origem ele atribui ao domínio do sagrado. A inviolabilidade da propriedade proviria de costumes religiosos, que sacralizada a terra onde os antepassados encontravam enterrados. Essa sacralização foi repassada, segundo seu pensamento, para seus detentores. Para Durkheim, o direito sagrado da propriedade privada provém do fato que a terra se sacralizou em função dos ritos religiosos executados sobre os túmulos dos antepassados, os quais, estando mortos, se aproximaram dos deuses aqueles que dela usufruíam, transformando-os também em divindades. Então, o direito ao usufruto da terra, inviolável, que cabia aos deuses, com a evolução se deslocou para as coletividades e finalmente para seus representantes, indivíduos que se destacaram destas por suas qualidades:

Está explicado, dessa forma, um dos caracteres da propriedade familial coletiva, [...]. É que, nesse regime, as pessoas são possuídas pelas coisas, tanto, pelo menos, quando as coisas pelas pessoas. Os parentes não são parentes senão por explorar, em comum, certo domínio. [...] As coisas, ao contrário, o chão, e tudo quanto a ele tanja de perto, aí ficam para sempre, por ser inalienável o patrimônio (DURKHEIM, 1983, p. 149).

Dessa afirmação, ele deriva a evolução da propriedade coletiva para a propriedade privada territorial, influenciado pela teoria de seu professor, Fustel Coulanges, sobre o culto aos mortos, passagem esta que transforma os homens em deuses, como também torna sagrada a terra onde os mortos repousam (DURKHEIM, 1983, p. 136-144).

O respeito à propriedade, portanto, não é, como tanta vez se diz, extensa, às coisas, do respeito imposto pela personalidade humana, seja individual, seja coletiva. Vem de fonte inteiramente outra, exterior à pessoa. Para saber de onde vem, cumpre indagar 
de como as coisas, ou os homens, adquirem caráter sagrado (DURKHEIM, 1983, p. 144).

São as leis que os prendem ao solo sagrado por eles explorado que, indiretamente, os enlaçam uns aos outros. Eis, de modo geral, de onde vem a espécie de culto do qual era objeto o campo familial, o prestígio religioso que era o seu junto aos espíritos. Esse prestígio não lhe vem, simplesmente, da grande importância da terra para os agricultores, nem da onipotência da tradição, mas singelamente, do fato de o solo, já por si mesmo, esta todos embebido de religiosidade. Era a coisa santa, de santidade muito mais comunicada à família que dela provinda (DURKHEIM, 1983, p. 150).

Sua análise permanece na aparência dos “[...] fatos sociais [...]”, não vai à raiz das suas determinações. A propriedade privada é tratada no quadro dos "[...] direitos reais [...]", que regem as relações entre coisas e pessoas: "Pode-se portanto dizer, em suma, que os direitos reais compreendem o direito de propriedade sob suas diversas formas (propriedade literária, artística, industrial, mobiliária, imobiliária) e suas diferentes modalidades, tais [..]." (DURKHEIM, 1999, p. 92).

Esse equívoco, que Durkheim (1999) apresenta na sua leitura sobre a sociedade moderna, encerra o autor dentro de uma camisa de força que repercute em toda a sua obra, inclusive na sua concepção de cidade. Em sua perspectiva histórica limitada ao evolucionismo (mesmo que os fatos, objeto de sua análise, sejam considerados sociais), seu método de análise é extraído das ciências naturais. Tanto que ele chamou de Física dos costumes o conjunto de suas concepções, fenômenos enquadrados dentro da moral (conjunto de fatos, representações e atitudes sociais detectáveis nas relações sociais).

\section{CONCEPÇÃO DE CIDADE EM WEBER}

Em Economia e Sociedade, Weber (1999) aborda, especificamente, o fenômeno urbano, num capítulo intitulado A dominação não-legítima (Tipologia das cidades) ${ }^{9}$. E é em decorrência desse estudo que

\footnotetext{
${ }_{9}^{9}$ Com os seguintes subtítulos: 1 . Conceito e categorias da cidade; 2 . A cidade de ocidente; 3. A cidade de linhagens na Idade Média e na Antiguidade; 4. A cidade plebeia; 5. Democracia na Antiguidade e na Idade Média (WEBER, 1999, p. 408-517).
} 
Weber é considerado um dos fundadores da Sociologia urbana ${ }^{10}$. $O$ estudo realizado por Weber trata a cidade como um sistema peculiar de forças, que só podia surgir em condições sociais particulares, num momento historicamente determinado. Buscando superar as abordagens existentes à época, principalmente as realizadas por Simmel, Weber encontra, na pesquisa histórica e comparativa, entre a cidade antiga e medieval no oriente e no ocidente, os elementos de compreensão do fenômeno urbano em sua diversidade.

Julien Freund"11 (1975) faz um resgate dessa análise, identificando a seguinte contribuição de Weber (1999, v. 2, p. 408-517):

1) Construiu um tipo ideal de cidade;

2) Deu um tratamento original à cidade ocidental, em relação às demais cidades do resto do mundo, do ponto de vista da racionalização;

3) Identificou as variedades da racionalização urbana no Ocidente; e 4) Indicou as consequências políticas dessa racionalização.

Este intérprete de Weber (FREUND, 1975) distingue dois tipos de cidade no pensamento weberiano: as de consumo e as de produção. Muito embora em ambas existam mercado, multiplicidade de ofícios, centro administrativo e guarnição, elas se diferenciam pela natureza das relações de troca desenvolvidas por seus habitantes. No primeiro tipo de cidade, seus habitantes dedicam-se, essencialmente, ao consumo, constituídos de funcionários ou de rentistas - vivendo de renda fundiária ou renda capitalista - ou, ainda, de aposentados, os quais usufruem de uma pensão do Estado. No segundo tipo, diferentemente, seus habitantes estariam essencialmente aplicados à produção, especializando-se em atividades industriais ou comerciais, podendo agregar também, nesta categoria, um terceiro subtipo, "a cidade de circunscrição agrícola”, predominante na sociedade antiga e medieval.

Entendemos que, em sua tipologia de cidade, este autor adota uma perspectiva abrangente, valorizando sua base material, ou seja, a dimensão econômica, juntamente com os aspectos da pro-

\footnotetext{
${ }^{10}$ Algumas controvérsias em torno desse texto foram observadas por Bruhns (2001).

${ }^{11}$ Julien Freund é conhecido no Brasil como divulgador da obra deste clássico da sociologia, especialmente com a Sociologia de Weber (2000).
} 
cessualidade política. Desse modo, estudou a cidade moderna como fenômeno ocidental iniciado na bacia do Mediterrâneo, e sua expansão para a Europa, enfatizando:

a) A função do mercado, que possibilita as trocas de forma regular;

b) Os componentes relativos à atividade artesanal ou industrial;

c) Um conjunto de ofícios diferenciados, em oposição à aldeia;

d) As funções jurídicas, econômicas e políticas, que movimentam a cidade, com a dominância de alguma delas.

Igualmente a Durkhiem, Weber toma a circulação como ponto de partida de sua análise. Domingues (2000, p. 210) ressalta a centralidade do mercado na sua concepção de cidade, vinculada não apenas ao fornecimento de produtos para atender às necessidades do príncipe e de sua corte, mas à polarização que exerce sobre as relações de seus habitantes.

Weber constrói tipologias a partir da preponderância de elementos registrados na observação das cidades, regidas pelas atividades industriais e comerciais - cidades de produção -, e regidas pela troca - cidades de consumo, dependentes da circulação do que é produzido em outras cidades. A estas agrega, também, outro conjunto de determinações para o surgimento e desenvolvimento urbano: aquelas de natureza política:

[...] nessas observações de uma 'política econômica urbana', um 'território urbano' e 'autoridades urbanas' já indica que o conceito de 'cidade' ainda pode e deve ser incluído em outra série de conceitos, além das categoriais econômicas até agora mencionadas exclusivamente - a saber: nas categorias políticas (WEBER, 1999, v. 2, p. 415).

Identificamos, ainda, na obra desse clássico, dois subtipos de cidade: a cidade-principado e a cidade-fortaleza, predominantes da Antiguidade à Idade Média (WEBER, 1999, v. 2, p. 415-425). Em cada uma, a atividade econômica ocorria em função da corte do príncipe ou da atividade de defesa.

Embora considere que a cidade ocidental, na passagem do Feudalismo para o Capitalismo (Idade Média), tenha assumido algumas características das asiáticas, portando, em seu interior, 
um mercado, ser localização da indústria, e constituir-se em fortaleza ${ }^{12}$, diferenciava-se delas, e daquelas existentes na Antiguidade, quanto ao direito fundiário, afastando-se do estatuto jurídico das terras camponesas:

[...] um fator essencial que nunca faltava: dentro da cidade, havia bens de raiz hereditários em princípio livremente alienáveis, isentos de censo ou apenas sujeitos a um censo fixo, e, fora da cidade, terras de camponeses vinculadas nas formas mais diversas a um senhor territorial ou à comunidade de aldeia, ou ambas as coisas (WEBER, 1999, v. 2, p. 426).

Mas a cidade ocidental agregava outra diferença, quanto à situação jurídica dos indivíduos, desta vez de forma absoluta e não mais relativa, nesse momento de transição da sociedade feudal para a sociedade capitalista, a urbes consiste em "[...] um lugar de ascensão da servidão à liberdade” (WEBER, 1999, p. 427). Seu destaque é para o processo de liberação da força de trabalho, dos elos extraeconômicos que prevaleciam na Antiguidade e Idade Média, como também de seu significado enquanto meios de produção:

A circunstância de que a cidade era um mercado, com oportunidades relativamente constantes de ganhar dinheiro no comércio ou no artesanato, era para muitos senhores um motivo para não explorar seus escravos ou servos na própria casa ou empresa como mão-de-obra, mas sim como fundo de renda - isto é, treinavam-nos como artesãos ou pequenos comerciantes e depois mandavam-nos, eventualmente (assim, na Antiguidade) abastecidos com meios de produção, à cidade, onde exerciam uma atividade aquisitiva, em troca de pagamento de um censo pessoal [...]. A possibilidade de comprar a liberdade aumentava o rendimento econômico especialmente dos pequeno-burgueses não-livres, e por isso não é nenhum acaso que, na Antiguidade e na Rússia, precisamente nas mãos dos libertos se acumulava uma grande parte dos primeiros patrimônios adquiridos em empreendi-

\footnotetext{
${ }^{12}$ Abrigava também "[...] propriedades feudais e sedes de linhagem com senhorios territoriais fora da cidade e, muitas vezes, também com grandes propriedades fundiárias dentro da cidade, incrementadas com o resultado da participação destas linhagens nas oportunidades lucrativas da cidade" (WEBER, 1999, v. 2, p. 426).
} 
mentos racionais de caráter artesanal ou comercial (WEBER, 1999, v. 2, p. 427).

Para Freund (1975) a originalidade da cidade ocidental estaria, primeiramente, no usufruto da autonomia, não encontrada nas outras cidades estudadas por Weber, na medida em que decide livremente (algumas vezes, com a participação do conjunto da população) quanto à nomeação de suas autoridades; usufrui de uma constituição própria, tornando cada habitante um cidadão da cidade; e dispõe também de um direito de propriedade.

Na cidade ocidental, dado seu caráter autocefálico, seus dirigentes não são nomeados por uma autoridade externa, na medida em que dispõe de soberania, designa seus magistrados, tem um direito próprio - dispondo de aparelho judiciário autônomo - e possui, em geral, impostos próprios, com independência financeira, mesmo cunhando suas próprias moedas.

Embora que o usufruto desse princípio - de comuna livre - não seja igual em todas as cidades ocidentais, este caráter lhes é peculiar, bem como a subordinação dos seus cidadãos exclusivamente a sua jurisdição e não, como no caso oriental, ao clã de origem ou ao grupo de parentesco. "Weber insiste quanto a este propósito sobre a influência do cristianismo que quebrou o sistema de parentesco no Ocidente ao lhe retirar toda a significação ritual" (FREUND, 1975, p. 52). O nascimento da associação urbana autônoma e autocéfala da Idade Média, com o seu conselho municipal, seu cônsul, maior, alcaide ou burgomestre foi, do ponto de vista jurídico-formal, uma usurpação revolucionária, resultado de uma socialização política dos burgueses contra os poderes legítimos, do nobre soberano, que, mais tarde, outorgará a confirmação jurídico-formal desta situação. Cidades mais novas já foram fundadas dentro deste estatuto pactuado ou outorgado.

Essa revolução, da qual fala Weber (1999), era realizada por uma conjuração entre burgueses, que pactuavam para uma determinada finalidade e por um determinado período de tempo. O poder militar era um elemento essencial daqueles que participavam da conjuração. Para completar a usurpação revolucionária, aqueles funcionários eleitos para ocuparem os cargos públicos, se apro- 
priavam de parte ou da totalidade do poder judicial, do comando de guerra e de todos os assuntos do município. A constituição de cidades, com um ajuntamento ou comuna, como órgão administrativo próprio dirigido por um conselho nomeado autonomamente pelos burgueses, foi consequência de grandes lutas; teve forte resistência de alguns monarcas e principalmente da igreja que desejava para si o governo das cidades. Em algumas situações, houve administrações mistas com Conselhos compostos por ministeriais e burgueses, mas, na maioria dos casos, era o burgomestre a figura que acabava sendo colocada em primeiro lugar. ${ }^{13}$

Ao colocar o exemplo da Itália, Weber (1999) explica como o Parlamento, do qual eram parte os proprietários de terra da cidade, foi se convertendo em uma reunião pública, na qual se aprovavam por aclamação as propostas dos notáveis ou se reclamava contra elas, mas, apesar disto, o povo não decidia verdadeiramente as eleições e as medidas da administração urbana. O monopólio dos notáveis na administração das cidades se mantém até o aparecimento de fortes contrastes com os interesses da burguesia excluída. Durante este período, a burguesia excluída tinha se desenvolvido econômica e educativamente, o que a fazia suportar com grande peso a sua condição. Segundo Weber, esta situação possibilita novas revoluções, nas quais os porta-vozes são as corporações burguesas (diferentes das corporações de artesãos).

Em Weber (1999), a cidade ocidental adquire um caráter específico e de maior relevância, na medida em que a situa na origem do desenvolvimento do Capitalismo e na formação dos Estados-nação, diferindo-a de outros tipos de cidade, dado seu caráter de racionalidade.

Souza vai dar um destaque para a questão da racionalização ocidental, cuja interpretação

[...] põe em evidência lógicas imanentes de racionalização que nos permitem pensar que certa necessidade, que não deve ser concebida de forma

\footnotetext{
${ }^{13}$ Esta figura aparece na Alemanha no século XIV e se diferencia da figura do cônsul que representa as linhagens, o burgomestre é um homem de confiança da união dos burgueses. Para ser membro da associação dos burgueses, era requisito a posse de propriedade territorial urbana, transmissível por herança, inalienável, livre de servidão, de pagamento de contribuição ou rendas, sendo somente submetida a um imposto para a cidade.
} 
absoluta, resulta do desenvolvimento histórico, como se, uma vez colocados para os homens, certos dilemas exigissem resolução, a qual se dava ademais em duas direções apenas - ascética ou mística (SOUZA, 2000, p. 225).

Registra, mesmo com reservas, a validade universal da espécie ocidental de racionalismo, em todas as esferas diferenciadas da vida social. Quanto ao projeto emancipatório da modernidade, Souza pensa a necessidade de se ultrapassar ambiguidades, particularmente quanto ao papel da razão moderna e do liberalismo. Destaca a conotação trágica da visão de homem moderno, em Weber; no entanto, há aspectos em sua obra que nos ajudam a pensar tal projeto, bem como as transformações dos modos de vida. Observa, nesta direção, a valorização das formas de solidariedade social que registrou no seu estudo das cidades, enquanto um tipo peculiar de racionalização, emergido num determinado espaço-tempo. Para ele, coloca-se a necessidade de

[...] repensar os tipos de transformação postulados por Weber como sendo aqueles produzidos por um indivíduo com qualidades 'extra-mundanas', o líder carismático, ou aqueles sistemicamente administrados por uma burocracia racional. Processos derivados da criatividade, contingente, exercida por subjetividades coletivas, devem receber a atenção que merecem, o mesmo sendo verdadeiro no que tange à reflexividade concebida de modo amplo, e não redutível portanto à racionalidade (SOUZA, 2000, p. 227-228).

\section{CONCEPÇÃO DE CIDADE EM MARX E ENGELS}

A cidade em Marx e Engels não se constituiu em objeto particular de análise. Ela é dimensão presente, real e objetiva no processo de gênese, consolidação e desenvolvimento da sociedade burguesa. Diferentemente de Durkheim e Weber, a crítica do capitalismo é orientada pela necessidade histórica de sua superação. Esses dois revolucionários se diferenciam, especialmente, por adotar o ponto de vista do operariado industrial, enquanto classe que porta interesses inconciliáveis com os interesses da burguesia. Como diz José Paulo Netto, em suas aulas, a particularidade de sua obra está nos pilares sobre os quais se ergue: a perspectiva da revolução, o método dialético e a teoria do valor trabalho. 
No livro A ideologia Alemã, escrito por Marx e Engels em Bruxelas/Bélgica, em 1845-1846, encontra-se uma fecunda análise da origem da cidade capitalista: "A maior divisão do trabalho físico e intelectual é a separação entre cidade e campo" (MARX; ENGELS, 2007, p. 75). E o início dessa separação entre cidade e campo pode ser observado "[...] com a passagem da barbárie à civilização, do regime tribal ao Estado, da localidade à nação, e se mantém ao longo de toda a história da civilização até chegar aos dias de hoje" (MARX; ENGELS, 2007, p. 75). Com a urbanização, surgem novas necessidades sociais, inclusive é na cidade que nasce o fenômeno da política (termo originário da polis, ou cidade), como exemplificam Marx e Engels: a necessidade da administração, da polícia, dos impostos etc.

Nesse trecho, d'A ideologia Alemã, aparece uma arguta definição de cidade, diferenciando-a do campo: "A cidade já é obra da concentração da população, dos instrumentos de produção, do capital, do desfrute e das necessidades, ao passo que o campo representa o expoente cabal ao fato contrário, quer dizer, ao isolamento e à solidão" (MARX; ENGELS, 2007, p. 75). Essa divisão social, entre cidade e campo, somente existe no contexto da propriedade privada e da expropriação incessante dos meios de produção, cuja superação é condição para se alcançar a plena emancipação social.

Para estes autores, o processo histórico de desenvolvimento das cidades, na Idade Média, se deve, basicamente, às novas formações constituídas por servos que se libertavam do jugo feudal. Suas determinações vinculam-se aos diferentes ofícios que surgiram, sob a organização dos artesãos em um sistema de corporações, entre elas:

[...] A concorrência dos servos fugitivos que constantemente afluíam à cidade, a guerra contínua do campo contra os centros urbanos e, como consequência disso, a necessidade de um poder militar organizado por parte das cidades, o nexo da propriedade em comum sobre determinado trabalho, a necessidade de dispor de lojas comuns para vender as mercadorias, em uma época em que os artesãos eram ao mesmo tempo commerçants, e a 
conseguinte exclusão dessas lojas dos indivíduos que não pertenciam à profissão, o conflito de interesses entre uns e outros ofícios, a necessidade de proteger um trabalho aprendido com muito esforço e a organização feudal de todo país [...] (MARX; ENGELS, 2007, p. 76).

Assim, progressivamente, nasce, na cidade, a plebe, constituída, originalmente, de servos que fugiam do campo dominado pelo poder feudal, e chegavam às cidades em busca de trabalho remunerado. Mas a divisão do trabalho continuou a se expandir, alimentada pelo desenvolvimento das forças produtivas materiais (meios e instrumentos de trabalho): surgiu a separação entre produção e comércio, com uma classe particular de comerciantes, separação essa herdada das cidades históricas tradicionais, que se apresentou nas recentes formações citadinas:

[...] Com isso, se estabelecia a possibilidade relações comerciais que fossem além dos arredores imediatos, possibilidade cuja realização dependia dos meios de comunicação vigentes, do estado de segurança pública alcançado no país e condicionado pelas circunstâncias políticas (é sabido que durante toda a Idade Medieval comerciantes andavam por aí em caravanas armadas) e das necessidades mais primitivas ou mais desenvolvidas das zonas acessíveis ao intercâmbio, condicionadas a seu correspondente grau de cultura (MARX; ENGELS, 2007, p. 78-79).

O desenvolvimento do comércio e a consequente criação de uma fração do capital gozando de relativa autonomia levaram as cidades a um maior intercâmbio, numa relação recíproca entre produção, circulação e troca das mercadorias. Além de circularem os meios de consumo, novos meios de produção também eram deslocados de uma para outra cidade, sendo que "[...] a divisão entre produção e intercâmbio logo evoca uma nova divisão entre as cidades tomadas individualmente, entre as quais cada uma em pouco explorará um ramo preferencial da indústria [...]" (MARX; ENGELS, 2007, p. 79), fazendo desaparecer gradualmente a restrição de troca do artesanato, que antes se encontrava limitada ao espaço local. 
A fração social constituída de comerciantes, que alcançou uma relativa autonomia dos artesãos, desde cedo, constituiu um capital móvel (desvinculado da terra, capital imóvel no quadro do Feudalismo, isto é, que não circulava), primeiro avanço que ultrapassa os limites naturais daquela sociedade. Para Marx e Engels (2007), o segundo avanço veio da manufatura, que, além de aumentar o capital investido na produção, também contribuiu para a mobilidade deste.

A expansão do comércio provocada pela descoberta da América e de um novo caminho marítimo para as Índias Orientais impulsionou o desenvolvimento da manufatura, mas, especialmente, deu um passo em direção a uma nova fase do desenvolvimento histórico. Novos produtos importados desses lugares, especialmente grandes quantidades de ouro e prata que entraram em circulação, alteraram totalmente a posição das classes, umas em relação às outras, e aplicaram duro golpe na propriedade feudal da terra e nos trabalhadores, enquanto cresciam as expedições de aventureiros, a colonização e, sobretudo, a expansão de mercados até a formação de um mercado mundial (MARX; ENGELS, 2007, p. 83).

A expansão do comércio e da manufatura, acompanhada da acumulação do capital móvel, criou a base material para o surgimento da grande burguesia, e dominou as cidades. Corporações e pequena burguesia tiveram que "[...] se curvar sob a dominação dos grandes comerciantes e manufacturiers” (MARX; ENGELS, 2007, p. 83).

Nesse mesmo período histórico, outra fração do capital começa a se tornar relativamente autônoma: o capital financeiro. Com o fim das proibições de exportação de ouro e prata e o surgimento do comércio de dinheiro pelos bancos (o dinheiro se torna uma mercadoria), aparecem diversos instrumentos ligados a esse processo: as dívidas públicas, o papel-moeda, a especulação com ações e fundos de investimento, a agiotagem em todos os artigos e a instalação do sistema monetário em geral (MARX; ENGELS, 2007, p. 86).

A Inglaterra passou a usufruir das melhores condições materiais: concentração do comércio e da manufatura; e criação de um mercado mundial para seus produtos. Com o aumento da demanda de produtos manufaturados, as forças produtivas tiveram que ser substituídas por outras mais aperfeiçoadas. 
Esse processo, para Marx e Engels, deu origem ao terceiro período histórico, com o surgimento da grande indústria e a transformação de todas as relações naturais em relações mercantis:

[...] A grande indústria universalizou [...] a concorrência (ela é a liberdade prática de comércio, os impostos alfandegários de proteção não passam, dentro dela, de um paliativo, uma defesa dentro da liberdade comercial), criou os meios de comunicação e o moderno mercado mundial, submeteu o comércio, transformou todo o capital em capital industrial e engendrou, com isso, a rápida circulação (o desenvolvimento do sistema monetário) e a centralização dos capitais [...]. Criou pela primeira vez a história universal, fazendo com que toda nação civilizada e todo indivíduo, dentro dela, dependessem do mundo inteiro para a satisfação de suas necessidades, acabando com o exclusivismo natural e primitivo de nações isoladas [...]. Colocou a ciência da natureza sob o controle do capital e arrancou a última aparência de regime naturalda divisão do trabalho. Em termos gerais, acabou com todas as relações naturais, na medida em que foi possível fazê-lo dentro do trabalho, e reduziu todas as relações naturais a relações fundamentadas no dinheiro. [...] (MARX; ENGELS, p. 86-87).

Daí resulta o surgimento das grandes cidades, "[...] nascidas da noite para o dia. [...]" (MARX; ENGELS, 2007, p. 86-87). E, dessa maneira, a cidade se torna superior ao campo. A grande indústria criava "[...] em geral, e por toda a parte, as mesmas relações entre as classes da sociedade e aniquilavam com isso a peculiaridades das diferentes nacionalidades. [...]" (MARX; ENGELS, 2007, p. 87).

Em Os Grundrisse (2011), Marx (2011) desenvolve a trajetória histórica do surgimento da cidade capitalista, relacionando-o com o processo de surgimento da propriedade privada.

As condições coletivas da apropriação efetiva por meio do trabalho, os arquedutos, muito importantes entre os povos asiáticos, os meios de comunicação etc., aprecem então como obra da unidade superior - do governo despótico pairando acima das pequenas comunidades. As cidades propriamente ditas forma- 
ram-se, ao lado desses povoados, apenas em pontos especialmente favoráveis ao comércio exterior; ou onde o chefe de Estado e seus sátrapas trocavam sua renda (produto excedente) por trabalho, gastando-a como fundo de trabalho (MARX, 2011, p. 390).

Com o desenvolvimento da propriedade privada, o campo dá lugar à cidade, onde residem os proprietários da terra. "O campo aparece como território da cidade; e não o povoado, como simples apêndice do campo" (MARX, 2011, p. 390).

Marx associa a transição da propriedade coletiva para a propriedade privada, formas que antecederam a produção capitalista (MARX, 2011, p. 388-423), como produto histórico, ao surgimento da possibilidade de apropriação privada do excedente (com o desenvolvimento das forças produtivas materiais) através da exploração do trabalho alheio.

[...] Nas diversas formas em que o trabalho se relaciona com suas condições de produção como sua propriedade, a reprodução do trabalhador não é posta de modo algum por mero trabalho, mas o pressuposto de seu trabalho. Na propriedade fundiária isso é evidente; no sistema corporativo também tem de ficar claro que o tipo particular de propriedade constituída pelo trabalho não se baseia sobre o mero trabalho ou troca de trabalho, mas sobre uma conexão objetiva do trabalhador com uma comunidade e com condições dadas que ele encontra, e das quais parte como sua base. Elas são igualmente produto de um trabalho, do trabaIho da história universal; do trabalho da comunidade - de seu desenvolvimento histórico, que não parte do trabalho dos indivíduos singulares nem da troca de seus trabalhos. [...] Uma situação em que simplesmente seja trocado trabalho por trabalho seja na forma viva imediata, seja na forma de produto - supõe a dissociação do trabalhador de seu vínculo originário com suas condições objetivas, motivo pelo qual, por um lado, o trabalho aparece como mero trabalho, e, por outro, seu produto, como trabalho objetivado, ganha diante dele uma existência completamente autônoma como valor. A troca de trabalho por trabalho - aparentemente, a condição da propriedade do trabalhador - se 
funda na ausência de propriedade do trabalhador como base do trabalho] (MARX, 2011, p. 424-425).

Em O Capital Marx (2003a, p. 407) retoma a categoria da divisão do trabalho em sociedades nas quais imperam as relações de produção e de troca de mercadorias. "O fundamento de toda divisão do trabalho desenvolvida e processada através da troca de mercadorias é a separação entre a cidade e o campo. Pode-se dizer que toda histórica econômica da sociedade se resume na dinâmica dessa antítese [...]".

Ressalta que, desde a Idade Média, embora, no plano político, o campo (sede do poderio feudal) dominasse a cidade (exceto países, como a Itália, caracterizados por um desenvolvimento urbano excepcional), "[...] no plano econômico, a cidade sempre espoliava o campo, com os preços de monopólio, com o sistema de tributos, com as corporações, com a fraude mercantil direta e com a usura" (MARX, 2008b, p. 1057).

Marx enfatiza a relação direta entre o crescimento do processo de acumulação do capital na cidade e a criação de uma superpopulação relativa, com a geração de bolsões de pobreza: "Quanto mais rápido se acumula o capital numa cidade industrial ou comercial, tanto mais rápido é o afluxo do material humano explorável e tanto mais miseráveis as habitações improvisadas dos trabalhadores" (MARX, 2003b, p.767 e 768). E ainda observa que "Em função do fluxo e refluxo do capital e do trabalho, a situação habitacional de uma cidade industrial pode ser hoje suportável, para se tornar repugnante amanhã" (MARX, 2003b, p. 768).

A pesquisa sobre a situação dos trabalhadores no espaço de moradia, ou seja, fora da fábrica, focalizando suas condições de alimentação, de habitação e de saúde em geral, auxilia a "[...] esclarecer plenamente as leis da acumulação [...]” (MARX, 2003b, p. 758). Como também não se podem conhecer as causas da fome sem conhecer as leis econômicas que regem o capital:

Só conhecendo as leis econômicas conseguimos descobrir a conexão íntima entre os tormentos da fome das camadas trabalhadoras mais laboriosas e a dilapidação dos ricos, grosseira ou refinada, baseada na acumulação capitalista. Já a situação 
habitacional é fácil de entender. Qualquer observador desprevenido percebe que, quanto maior a centralização dos meios de produção, tanto maior o amontoamento correspondente de trabalhadores no mesmo espaço e, portanto, quanto mais rápida a acumulação capitalista, tanto mais miserável as habitações dos trabalhadores. Os "melhoramentos" urbanos que acompanham o progresso da riqueza, a demolição de quarteirões mal construídos, a construção de palácios para bancos, lojas etc., o alargamento das ruas para o tráfego comercial e para as carruagens de luxo, o estabelecimento de linhas de bondes etc., desalojam, evidentemente, os pobres, expulsando-os para refúgios cada vez piores e mais abarrotados de gente. Além disso, todo mundo sabe que a carestia do espaço para morar está na razão inversa da qualidade da habitação e que os especuladores imobiliários exploram as minas da miséria com menos despesas e mais lucros que os obtidos em qualquer tempo com a lavra das minas de Potosí [...]. Com o desenvolvimento da indústria, da acumulação do capital, com o crescimento e o 'embelezamento' das cidades, os males cresceram de tal modo que o simples medo das doenças contagiosas, que não poupam nem a respeitabilidade burguesa, motivou a promulgação pelo Parlamento de nada menos que 10 leis relativas à fiscalização sanitária, e a classe rica, aterrada em algumas cidades, como Liverpool, Glasgow etc., resolveu intervir por meio das municipalidades (MARX, 2003b, p. 763).

Portanto, seguindo Marx (2003b), numa pesquisa sobre o espaço urbano, há que se levar em consideração, além do nível de organização da luta de classes:

- a instalação de forças produtivas materiais e humanas (concentração de fábricas e aglomeração de força de trabalho que adensa o tecido urbano);

- e grau de condições gerais da produção capitalista implantadas em seu território (meios de comunicação e transporte, e, atualmente, meios de reprodução da força de trabalho).

Constitui condição material para a divisão do trabaIho na manufatura o emprego ao mesmo tempo de 
certo número de trabalhadores. De maneira análoga, a divisão do trabalho na sociedade depende da magnitude e densidade da população, que correspondem à aglomeração dos operários numa oficina. Mas essa densidade é algo relativo. Um país relativamente pouco povoado, com meios de transporte desenvolvidos, possui uma população mais densa do que um país mais povoado com escassos meios de transporte [...] (MARX, 2003a, p. 407-408).

Marx (2003a) indica a resultante do avanço da industrialização, acompanhada pelo amontoamento de população nos grandes centros urbanos: a ruptura do metabolismo social existente entre o homem e a natureza, com a destruição das condições naturais desse intercâmbio:

Com a preponderância cada vez maior da população urbana que se amontoa nos grandes centros, a produção capitalista, de um lado, concentra a força motriz histórica da sociedade, e, do outro, perturba o intercâmbio material entre o homem e a terra, isto é, a volta à terra dos elementos do solo consumidos pelo ser humano sob a forma de alimentos e de vestuário, violando assim a eterna condição natural da fertilidade permanente do solo. Com isso, destrói a saúde física do trabalhador urbano e a vida mental do trabalhador do campo. Mas, ao destruir as condições naturais que mantêm aquele intercâmbio, cria a necessidade de restaurá-lo sistematicamente, como lei reguladora da produção e em forma adequada ao desenvolvimento integral do homem (MARX, 2003a, p. 570).

Em todo O Capital, Marx explora o papel do espaço territorial e urbano, quando aborda suas principais categorias explicativas sobre a gênese e desenvolvimento da sociedade burguesa, o que torna esta obra leitura obrigatória nos estudos urbanos contemporâneos, especialmente para aqueles comprometidos com a emancipação social de toda humanidade. Suas explicações se exemplificam na remissão às modalidades de cidades: cidades puramente mercantis e cidades industriais (MARX, 2008a, p. 438 e 441).

Engels teve contribuições próprias sobre a questão urbana em vários escritos de sua autoria. No seu livro A Classe Operária na 
Inglaterra (1845) analisa o modo de vida da maioria dos habitantes da cidade, os proletários, no contexto de um acelerado processo de industrialização. Como um observador participante dos acontecimentos urbano-industriais da sua época, Engels assinala as contradições da vida urbana, recolhendo um conjunto de dados dentro do marco teórico do Materialismo Histórico. Para este autor, a situação da classe operária inglesa do século XIX é resultado de um processo rápido e radical, no qual são fatores causais a divisão do trabalho e as inovações tecnológicas (introdução da máquina a vapor no processo produtivo). Preocupado com as consequências sociais dessa enorme mudança, Engels afirma que a densidade urbana confere às relações sociais a impressão da indiferença, do isolamento e do conflito. Como lembra Lefebvre (1999), Engels introduz o tema da multidão solitária e da amotinação social. Na concepção de alienação, está o significado da prática na vida cotidiana, não somente no trabalho, mas também na família, na rua, ou seja, na vida citadina.

Uma atenção mais precisa sobre a moradia deve-se também a Engels (1986b), em trabalho posterior, intitulado Contribuição ao Problema da Moradia, escrito em 1872, obra que condensa uma longa polêmica com Proudhon. Engels interessa-se por uma solução definitiva do problema da moradia, que deve ser buscada na abolição do modo capitalista de produção, única via para acabar com as formas de apropriação que mantêm a moradia como um bem privado em proveito de uns poucos. Enquanto isso se processa, ele propõe uma solução conjuntural, a desapropriação dos atuais proprietários por parte dos miseráveis sem teto e dos operários que moram em condições deploráveis. A moradia, condição material da reprodução social no Capitalismo, adquire, em sua obra, destaque particular que oferece subsídios para tratar de inúmeros temas urbanos, inclusive das políticas públicas denominadas de interesse social.

\section{CONSIDERAÇÕES FINAIS}

Os pressupostos epistemológicos contidos nos escritos destes clássicos da Teoria Social subjazem as escolhas metodológicas e a direção política das contribuições de estudos e proposições operacionais que se tecem, atualmente, sobre as cidades, no Brasil e no mundo. 
Weber (1999) contribuiu para a compreensão da formação da cidade, do surgimento à sua consolidação, como sequência histórica de dominação ilegítima e legítima, que segundo seu ponto de vista, foi, processualmente, conferindo maior racionalidade à formação social capitalista e, portanto, à moderna cidade capitalista. O desenvolvimento de uma burocracia administrativa que racionaliza as funções do poder legítimo encontra-se na gênese da formação do Estado-nação no Capitalismo moderno e demarca uma nova fase histórica na qual a cidade perdeu sua autonomia política, militar e jurídica, sendo novamente submetida pela institucionalização do Estado Moderno.

A cidade em Durkheim (1999) é uma organização social complexa, na qual a divisão do trabalho chegou a alto grau de diferenciação, resultado da combinação de volume, densidade material e moral. A industrialização acelerada impediu uma organização adequada da divisão do trabalho social, deixando espaço a situações provocadoras de conflito, anomia e desigualdade que só serão harmonizadas por regras jurídicas comuns a todos. Sendo assim, este autor outorga ao direito positivo o papel da consciência coletiva das sociedades tradicionais.

Marx e Engels (2007) vão situar a cidade em relação ao desenvolvimento histórico da divisão do trabalho e as diferentes formas de propriedade. A crescente divisão do trabalho, a ampliação do comércio e as formas de propriedade, concebidas como produto do trabalho acumulado (produto do trabalho alheio apropriado pelo capital), transformam a cidade em cidade capitalista. Nela, se concentram, pela força da dinâmica imanente do Capitalismo, os meios de produção (forças produtivas materiais), as condições gerais da produção capitalista e a força de trabalho. As novas atividades produtivas levam ao aprofundamento da divisão entre trabalho físico e intelectual e, por consequência, a uma mais aguda divisão entre cidade e campo.

Buscamos sintetizar algumas das principais contribuições dos autores abordados, cujas obras são, sem dúvida, muito mais extensas e abrangentes que as indicações aqui expostas, com caráter introdutório e com objetivo de explorar panoramicamente a riqueza contida na Teoria Social Clássica e na economia política para compreender a cidade contemporânea. Resgatamos a concepção de 
cidade em Marx (2003a, 2003b, 2007, 2008a, 2008b e 2011), Engels (1986a, 1986b, 2007), Weber (1999) e Durkheim (1983 e 1999), privilegiando a visão com que cada autor contribuiu para desvendar a essência desta complexidade. Signatários de métodos de Teoria Social que permeiam os debates epistemológicos, imbricados em escolhas políticas, suas proposições, onde encontramos elementos similares, mas, também divergentes, continuam indispensáveis.

\section{REFERÊNCIAS}

BRUHNS, H. La ville bourgeoise et l'émergence du capitalisme moderne : Max Weber : Die Stadt (1913/14-1921). In : LEPETIT, Bernard; TOPALOV, Christian (Eds.). La ville des sciences sociales. Paris: Belin, 2001. Cap. 2, p. 47-78.

DOMINGUES, José Maurício. A cidade: racionalização e liberdade em Max Weber. In: SOUZA, José (Org.). A atualidade de Max Weber. Brasília: UnB, 2000.

DURKHEIM, Émile. Da divisão do trabalho social. São Paulo: Martins Fontes, 1999.

. Lições de sociologia: a Moral, o Direito e o Estado. São Paulo: T. A. Queiroz/Ed. Da Universidade de São Paulo, 1983.

ENGELS, Frederic. A Classe Operária na Inglaterra. In: MARX, K.; ENGELS, F. Obras escogidas, vol. I. Moscou: Ed. Progresso, 1986a.

. Contribuição ao Problema da Moradia. In: MARX, K; ENGELS, F. Obras escogidas, vol. II. Moscou: Ed. Progresso, $1986 \mathrm{~b}$.

FREUND, Julien. Sociologia de Weber. Rio de Janeiro: Forense Universitária, 2000.

.La ville selon Max Weber. Espaces et societé, Paris, n. 16, nov. 1975.

GIDDENS, Anthony. Política, sociologia e teoria social. São Paulo: UNESP, 1997.

ICASURIAGA, Gabriela Lema. Perspectivas teóricas sobre a cidade capitalista. 1997. Dissertação (mestrado) - Programa de Pós-Graduação em Serviço Social, Universidade Federal do Rio de Janeiro, Rio de Janeiro, 1997. Disponível em: <http://locuss. org/joomlalocuss/index.php?option=com_docman\&task=doc_ details\&gid=29\&/temid $=36>$. 
LEFEBVRE, Henri. A cidade do Capital. Rio de Janeiro: DP\&A, 1999. MARX, Karl. O capital: crítica da economia política: o processo de produção do Capital. Livro I, vol.1. Rio de Janeiro: Civilização Brasileira, $2003 a$.

. O capital: crítica da economia política: o processo de produção do Capital. Livro I, vol. 2. Rio de Janeiro: Civilização Brasileira, 2003b.

- O capital: crítica da economia política: o processo global de produção capitalista. Livro Terceiro, vol. IV. Rio de Janeiro: Civilização Brasileira, 2008a.

- O capital: crítica da economia política: o processo global de produção capitalista. Livro Terceiro, vol. VI. Rio de Janeiro: Civilização Brasileira, 2008b.

. Grundrisse. São Paulo: Boitempo, 2011.

MARX, Karl; ENGELS, F. A Ideologia Alemã. Rio de Janeiro: Civilização Brasileira, 2007.

RODRIGUES, José Albertino (Org.). Émile Durkheim. São Paulo: Ática, 1998.

SOUZA, José. Prefácio. In: SOUZA, José (Org.). A atualidade de Max Weber. Brasília: UnB, 2000.

WEBER, Max. Economia e Sociedade: fundamentos da sociologia compreensiva. Brasília, DF: Ed. UnB; São Paulo: Imprensa Oficial do Estado de São Paulo, 1999. v. 2. 